\title{
EMERGING TRENDS IN GERONTOLOGY AND GERIATRICS: IMPLICATIONS FOR THE SELF-CARE OF THE ELDERLY
}

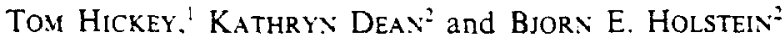 \\ 'Health Gerontology Program, School of Public Health, University of Michigan, 109 South Observatory, \\ Room M5112, Ann Arbor, MI 48109-2029. U.S.A. and 'Research Unit for Social Medicine. Institute \\ of Social Medicine, University of Copenhagen. 32 Juliane Maries Vej. DK-2100 Copenhagen. Denmark
}

\begin{abstract}
Increases in the world's older population have posed a significant challenge to available health care resources. For many older people, informal initiatives represent a necessary, rather than an optional health care strategy in the absence of alternatives. Those individuals with the greatest health and economic dependencies are often held responsible for their reliance on subsidized long-term care services. This tendency to blame the victim appears to transcend fundamental philosophic differences which have traditionally distinguished some collectivist and individualist societies.

Although health care has been viewed traditionally by health professionals as their domain, self-care and lay initiatives have recently been recognized by professionals as important to the health care of different population groups including older people. The concept of self-care has been used in various ways by different people to describe a wide range of personal health behaviors encompassing lay care. self-help, enlightened consumerism, and various preventive measures as antidotes to the impairments of old age. This paper reports some of the outcomes of an international project which reviewed geriatric self-care in different countries and health care systems. Various influences on the evolution of interest in geriatric self-care were identified including: similarities and differences in health care systems: demographic changes: cohort differences; the emergence of professionals with specialized training in geriatric health care; and. the salience of biomedical models in addressing the health problems of aging.

The role of professionals. especially those trained in geriatrics, is examined with an acknowledgment of the importance of a self-care strategy that is independent of professional dominance. The increasing inadequacy of health care systems to deal with a burgeoning older population makes it especially important for professionals and consumers to work together on the development of health care initiatives which decrease dependency on formal services and support positive health behavior. As more people move into old age, an increasing number will be better informed about their own health and about the health care system, and also more interested in prevention and health maintenance. They may also be less likely to defer to the professional's judgment in making health care decisions.

This paper concludes with a caution regarding self-care as a potential 'two-edged sword.' For the somewhat healthier and better educated elderly, effective self-care will be an important tool of prevention, health maintenance, and consumer protection. For the chronically impaired and most dependent elderly. self-treatment may be their only, and often inadequate resource.
\end{abstract}

Key words - self-care, elderly, political systems, bio-medical model, geriatric care

The rapid development of a knowledge base in gerontology and geriatrics has progressed in a somewhat typical fashion, resulting in a wide range of approaches to the study of health care in late life. For example, the currently popular concept of self-care, which has not previously carried any special agerelated connotations, can be found in many recent writings by gerontologists in both the social sciences and the health care professions. When reviewing this literature, the broad diversity of meanings which have been ascribed to self-care becomes immediately evident. Self-care has been used to describe a variety of phenomena ranging widely from preventive health medsures as a kind of antidote for aging, to enlightened consumerism, lay care and self-help. Self-care has also been suggested as a medical care alternative.

The various interpretations of self-care behavior, and its specific applications in late life, derive their origin from at least three different areas of the literature. The early writings of Mechanic, Kasl and Cobb, and others have provided a theoretical base for understanding the concept of personal health-related behaviors $[1,2]$. Others have viewed self-care and self-help as a kind of social movement $[3,4]$. In his more recent writings, Katz has furthered this notion with specific applications of the self-help movement to the elderly [5]. Current definitions of health-related and self-care behaviors in late life are based on what has been learned from various empirical investigations. Since many of the earlier investigations of health behavior focused predominantly on the use of professional services, our preliminary understanding of self-care has often been a derivative rather than a direct outcome of study. However, the concept of personal health behavior has been expanded by recent and ongoing population studies and some of the writings in medical anthropology, which have focused on a broader concept of self-care behavior [6-8].

In a recently published book, we tried to clarify the relationship of self-care and aging by identifying common or shared elements in different countries and settings [9]. Funded by the Kellogg International Scholarship Program on Health and Aging, this 
study attempted to identify common elements in the concept of self-care which have contributed to its wide acceptance in different parts of the world. For example, there was consensus around the notion that self-care is the basic form of care for all age groups. Levin has described non-professional care as a "hidden health care system," and suggests that as much as $75 \%$ of all health care is provided by lavindividuals without the involvement of professionals [10.11]. However, this is not to suggest that lay care and professional care are mutually exclusive. To the contrary, it is evident that self-care is interactive with the health care system.

It is also evident that individual health behavior is influenced by several personal characteristics including lifestyle, health beliefs, and habits. Health behav. ior often reflects individual perceptions of health status and personal concerns about health, quite independent of societal views or even of actual health status. Over time, it can reveal a consistent pattern of personal health perceptions and how an individual deals with health problems [12]. In his review of a number of studies of illness behavior and self-care, Ford concluded that there are relatively constant patterns throughout the life span [13]. From various studies of geriatric health behavior which have been conducted, there has also emerged a description of an elderly population with quite distinct patterns of health behavior [14-16].

Our review suggested further that individual health behavior is being viewed increasingly as an important element for maintaining a healthy lifestyle. There is mounting epidemiologic data to document the behavioral components of disease and its prevention [17]. Health reports from different countries continue to substantiate the significance of lifestyle and modifiable behavior in the interpretation of national morbidity data. Moreover, as more people live longer, with chronic disease contributing notably to morbidity, the impact of lifelong health behavior patterns becomes increasingly evident. Health status in old age may be more closely related to chronic disease and lifestyle than to biological aging. However, the somewhat narrow view of health behavior as caretaking in the presence of disease, and compliance with medical regimens, has clearly broadened to encompass the range of self-care, including selftreatment and preventive actions, related behaviors of a general nature which individuals do for their health, and interactions with health care professionals. Thus, health enhancing self-care is important for healthy individuals as well as for those who are chronically ill [9].

The increasing number of older people in society has too often led to their portrayal as a 'social problem.' Consequently, professional services have been developed for them as passive recipients, rather than as full participants. More active and assertive self-care may thus appeal to the fundamental need which older persons have for autonomy and for maintaining a degree of control or balance in their relationships with professionals and in their interactions with an often inadequate health care system [18].

An important aspect of self-care is the belief or perception that 'it works.' Indeed, the few studies conducted by physicians suggest that it does work [8] From a lifetime of experiences with their personal health, many older persons are aware of what can be effective in either a preventive or remedial way. without the need for consulting a health care professional $[8,18]$. Also, they often recognize the healthy outcomes of preventive lifestyles and practices.

Of course. there is always the danger that the concept of self-care can become exploited into another form of 'medical quackery." with the elderly once again as prime targets. This concern, however. is not likely to have a significant impact on the growing recognition of the importance of selftreatment by the elderly as something that often works for them, or is at least as effective as any of the alternatives. Self-care is often a countering offense against inadequate or inappropriate professional ser. vices, as well as against ageism itself [18].

Our review suggests that professional and nonprofessional care should be viewed as interacting efforts to enhance health rather than as alternatives. Health professionals who face uncertainties and inadequacies in dealing effectively with older patients are becoming more inclined to re-examine traditional assumptions about the dominant role of the professional in determining optimal courses of health actions [18]. Thus, self-care and professional care decisions can be viewed by provider and consumer alike as complementary forms of health care

\section{THE SOCIAL CONTEXT OF HEALTH BEHAVIOR}

Our review also confirmed the importance of the social situation as a determinant of self-care and personal health behavior in late life. Some of the more obvious factors include: knowledge of and access to formal services; availability of family and other informal supports: and, various characteristics of the residential and community environments in which people live. Furthermore, although generally neglected in policy related to personal health behavior, the larger social context affects health-related behavior in a number of ways. Societal perceptions of the elderly, traditional definitions of the family, and prevailing economic policies are all important influences which affect health care and personal health behavior in the elderly.

A specific example of this is evident when one examines the accepted interaction of self-care with the health care system. On the one hand, the complementarity of self-care and professional care can be assumed. However, the critical elements in this interaction are viewed quite differently. One perspective might focus on adequate measurement of functional assessment, matching types of care appropriately with health needs, and examining the epidemiologic relationship of self-care with disease patterns. Empirical applications of this view are likely to be based on models of adaptation and healthy aging. An economic policy perspective of health behavior is likely to be quite different. Economically-based priorities in the interaction of self-care and formal services are more typically related to reducing service utilization rates and restricting eligibility criteria. The rationale 
or guiding framework for such a perspective is likely to be an economic or social problem model.

Thus, the implications of the social and political context for geriatric self-care should be evident. One can easily speculate about the differential effects of such societal influences on the funding of various research and demonstration activities on determining what types of self-care might be promoted, and on possible outcomes for deleting or restructuring formal geriatric health care services. As Estes and her colleagues have noted so accurarely: "... health, illness, and health care in old age are directly related to the nature of the society in which they occur" [19].

In our review and analysis of geriatric self-care in various countries, the assumption was made that the fundamental philosophical differences between health care systems would be evident in the patterns of self-care which have evolved, and in how such efforts would relate to long term health care policies and practices for the elderly. On at least a superficial level, differences appear to exist between the personal health behavior patterns of health care systems with different patterns of formal services and service eligibility and reimbursement criteria.

For example, the more formalized types of self-care observed in the United States seem to be characterized by a predominance of self-help and preventive activities designed to prolong fitness and good health and to promote and reinforce personal autonomy. Also, the self-care 'movement' in the U.S. appears to be largely independent of the medical care system. Philosophically, this focus is consistent with the individualistic view of the U.S. social system, where the ultimate responsiblity for medical care and good health rests with the individual. It is also consistent with a system which clearly distinguishes between medical care and health maintenance activities, as exemplified by its policy of public reimbursement to private institutions and skilled medical professionals.

This emphasis on self-help and personal autonomy does not seem as dominant in countries with more socialized or public health care systems, where patterns of self-care were found to be generally mixed. Self-treatment and lay care efforts have often evolved as 'gap-fillers,' or to complement available formal health care services. Moreover, families and informal community services for the elderly have more structural links with professional services. Although there is considerable variability between countries on this issue and its specific implementations, a continuum of social and medical, informal and formal care is more consistent with the philosophic underpinnings of public rather than privatized systems.

Although examining philosophical differences in health care systems may represent a useful starting point in describing self-care in different societies, the situation is much more complex than suggested by the preceding analysis. Welfare states differ greatly. They may share a similar collectivist belief in an egalitarian social system yet, for cultural, historical or economic reasons, they may vary considerably in how such ideas are put into practice. Also, health care policy in privatized systems does not remain static over time. Health care policy and financing structures in the U.S. in 1985, for example, are considerably different from what they were in 1980, and are likely to be further modified in the years ahead [19]. For example, an increasing trend which is likely to influence future policy decisions and the availability of public funds can be seen in the progressive decline in per capita days of institutional care

The above observations must also be tempered by the fact that biological models of aging have strongly influenced the evolution of self-help and self-care activities, regardless of structural and philosophic characteristics of the health care system.

The documentation of self-care and lay health initiatives in the less developed regions of the world is quite sketchy. However, it is evident that a high level of non-professional care takes place in many of these areas in the absence of formal services. The overwhelming majority of elderly in the lessdeveloped regions of the world have neither health care insurance nor regular access to formal health care services. In fact, $49 \%$ of the world's population reside in countries with neither private nor public forms of health insurance [20]. Self-care and lay care initiatives, treatments based on cultural or religious beliefs, and other informal care modes represent the primary source of health care for many of these populations [21]. In general, developing nations make greater use of traditional remedies and indigenous practitioners for reasons of cultural and economic history rather than as a consequence of established ideologic differences with industrialized countries. In many of these less-developed areas the full elaboration of a formal health care system remains a future issue. Moreover, since the label 'developing nation' masks considerable variability between countries, comparative analyses with other regions of the world might best be resisted.

It seems clear that making a straightforward comparison along collectivist vs individualist lines fails to account for important factors which influence the development of self-care for the elderly. Several factors appear to exert more influence on self-care than ideologic distinctions between social systems in determining the type and scope of self-care programs for the elderly in different parts of the world. Among the more obvious ones are: the economic implications of demographic changes; cohort differences; biomedical models of disease and professional care; and, the development of professional and policy initiatives in geriatrics. The remainder of this paper discusses the implications of these issues for self-care and lay health initiatives on behalf of the elderly.

\section{THE DEMOGRAPHIC AND ECONOMIC IMPERATIVES}

The graying of the population has been welldocumented, and need not be restated here. The median age of the populations of the industrialized countries of the world has been rising steadily in the presence of large numbers of people reaching age 65 and well beyond. Moreover, the elderly population in the less developed regions of the world, with successful records in eradicating many of the infectious diseases of early life, has also increased dramatically $[22,23]$. However, the actual numbers of elderly people in these areas have generally remained small enough for specialized geriatric health care to be only 
a distant priority. Thus, self-treatment and lay care may continue to be the primary source of health care for these growing populations of elderly. Indeed, recommendations of various world health bodies have stressed the importance of strengthening and improving such informal health care strategies, rather than supplanting them-e.g. at the 1982 World Assembly on Aging, the World Health Organization proposed a principle of greater involvement of the elderly and their families in determining modes and practices of health care [21].

In many of the industrialized nations, however, a different approach has been emerging. The presence of a growing number of elderly persons-many with both economic and health dependencies-is likely to reinforce the view of old people as a 'social problem,' requiring a societal-level solution. Yet, the staggering costs of long-term care demands have resulted in political and economic problems in most countries, and are potentially in conflict with the development of an adequate collectivist solution. The economic issues for welfare states specifically, have resulted in some instances in a shift towards a more individualistic approach to geriatric care [24-26].

A conservative, or anti-welfare, philosophy is presently influencing the health care policies in the widely different systems studied [26,27]. For example, although the health policies of the U.K. and the U.S. remain different in principle, there are similar conservative overtones in actual practices. In both countries, the elderly are increasingly being 'scapegoated' for consuming a disproportionate share of society's resources (e.g. 11-14\% of the population accounting for $30-40 \%$ of its health care costs). National retirement pension systems have been challenged repeatedly in recent years, and similar questions have been raised regarding the subsidization of special programs for the elderly over services for children and others in society $[28,29]$. A more widespread trend is emerging-especially in the United States-to 'blame the victim.' Older people are the cause of this societal problem, the argument goes, and others should not have to bear the costs of solving it [24]. This argument has gained a wide audience despite the fact that other countries manage to provide better health and social services, often free of cost, while spending proportionately less of their gross national product on health care.

The implications of conservative policies for resource allocation include restricted eligibilities for long-term care services, reduced service access and, generally, an overall decline in the availability of formal health care options. The development of strategies of lay and self-care, and related informal efforts becomes a forced choice either to supplement or to replace declining availability of professional health care. Thus, the encouragement of self-care and lay health initiatives during this conservative period may arise from fiscal considerations rather than from concerns for health and well-being.

Consequently, it becomes increasingly evident that some elderly individuals will be successful in having their health care needs met, while others. less fortunate economically and physically, will not. For this latter group, self-treatment may become a 'stop-gap' or the only option, while for their more advantaged age peers, the practice of self-care will be more closely linked with preventive measures and actions which reinforce their autonomy and assist them in decisionmaking as consumers of health care services. The collectivist and egalitarian characteristics of some welfare systems are becoming diluted. narrowing the ideologic distinctions between different types of health care systems in their applications of self-care

\section{COHORT CHANGES}

Much of our understanding of the health care practices of the older population is based on present and past cohorts of elderly in the industrialized world. Yet we know that emerging and future generations of elderly are markedly different. They are more educated, healthier, and. for the most part, better-off financially [12]. As a consequence, they should be better able to understand their health carc system and, perhaps, how to negotiate it more successfully than their predecessors. Future cohorts are more likely to have a heightened understanding of their own personal health and to be less deferential to the medical authority of the physician. General improvements in their health status should mean that they will be healthier longer, delaying significant chronic impairment until very advanced ages.

The emergence of a large number of persons with four and five generations family ties suggests further that increasing numbers of middle-aged adults are experiencing a very real socialization to the health dependencies of old age. Moreover, the caretaking of parents and other chronically impaired family members should foster the development of at least some basic skills for expanding the lay care network. Obviously, this projected trend will not be universal, nor will the stresses experienced by family caretakers in many countries be easily diminished [30]. However, given the inadequate distribution of long-term care services in many countries, and the widespread problems of access and eligibility, family members are increasingly likely to be involved at some level of caretaking. Therefore, regardless of existing differences in health-care systems, such cohort changes should strengthen and expand informal health care initiatives and self-care.

\section{THE ROLE OF PROFESSIONALS AND BIOMEDICAL MODELS OF CARE}

Care of the elderly in different countries is generally dependent upon a mixture of public and private services, with the more developed welfare systems based on structured linkages between family care and formal services on the local lcvel. Systems which rely on primary care provided by locally available general practitioners may facilitate the interaction of family and professional care. The small geographic size of many countries along with the relative homogeneity of their populations may also strengthen such linkages. However, this is not to suggest that family care in such countries is sufficient or adequate [30]. Demographic projections perhaps best exemplify the potential problems. For example, the very elderly British population-i.e. those 85 years and over who have the greatest health care needs-are projected to 
grow by $42 \%$ between 1976 and 1996 [31]. However, the principle of family responsiblity and informal care at the community level is well-established in the British health care system [25]. It has been further reinforced by the general unavailability of institutional beds throughout the country. Thus, a major role of local health care professionals is to work with the family in providing alternatives to care in public institutions.

Health care of the elderly in Demark is similar in that it is based on primary care provided by general practitioners. However, considerable emphasis is also placed on in-home services and home health aids designed to avoid or postpone institutionalization. Responsibility for care of the elderly, however, rests primarily with the general medical practitioner, while the British and U.S. have developed systems which rely more on specialized geriatric care.

An important related question which continues to receive attention deals with just how lay and professional care should be linked. There have been varied approaches to this issue, with some concern expressed about professional dominance, and the importance of retaining patient autonomy and lay control in health care decision-making $[3,5,32,33]$. The compatibility of professional with lay care activities, however, seems evident $[34,35]$. For example, the Kanes have suggested that, since the elderly will continue to use the formal health care system regardless of its inadequacies, a most useful form of self-care for them would be to learn how to better utilize the existing system [35]. In so doing, they are both gaining and delegating control rather than simply empowering the system to render them dependent upon it.

The development of health care policy and services in the United States has differed from many other countries by its emphasis on an institutional model and its related biomedical and technological solutions to health problems. This has tended to further separate lay and professional care. Hospitals have been the primary locus of health care, with nursing homes closely resembling them. The major health care policies for the U.S. elderly population (i.e. Medicare and Medicaid) were designed, in large part, to underwrite the costs of institutionally-based services. The phenomenal growth in the number of nursing homes in the United States has gone hand-in-hand with the escalation of Medicaid costs. Until very recently, reimbursement policies have tended to exclude many necessary geriatric services which are delivered outside the institution. Even those which are presently covered are based on biomedical models of disease and on an acute care framework, and provided by specially-trained health care professionals. Programs which enhance family skill and options in geriatric caretaking have been only at the periphery of health care policies and practices in the United States. This medical/institutional model preserves the dominance of the health care professional, and tends to encourage and reinforce dependency rather than self-care in geriatric patients [18].

This contrasts sharply with the health care in Denmark, where an extensive home care service has been implemented. In the majority of the communities, even 24-hr service provision has been established, and has taken over the responsibility for care of elderly who would otherwise have been institutionalized. The potential for promoting self-care and family initiatives is greater in this type of noninstitutional service framework.

In countries which have developed specialized geriatric care such as Great Britain and the United States, the role of professionals and the degree of patient and family involvement. are strongly influenced by the extent of policy emphasis on institutional care, and the consequent availability of institutional beds and services.

The socialization of health care professionals is also influenced by the dominant health policies of the society in which they are trained. The principal influence in the training of health care professionals across countries is still the medical model of caretaking. just as the social problem model pervades the training of social service professionals. Such disease models of caring run counter to activating lay participation in health care and maximizing functional health status.

\section{GERIATRIC DEFINITIONS OF HEALTH CARE AND POLICY}

The development of programs of self-care in late life will be influenced by emerging trends in geriatric care. One of the more important shifts in our thinking about geriatric care is that it is simply different: the health care needs of the chronically impaired elderly are more complex than those of other age groups, and less amenable to traditional responses by the health care system. Although this is not a new discovery, it has taken a long time to be fully recognized. The weakness of traditional care strategies-especially those based on medical and institutional models point to a need for change in the type and range of services, and major revisions in the training of professionals.

In some countries, schools of medicine. nursing, and the allied health professions have progressed rapidly with the development of coursework. clinical rotations, fellowships, and post-graduate programs in geriatrics. Although some might argue that such initial efforts have had minimal impact to date, the growth of sub-specialties and concentrations in geriatrics remains significant. These efforts are likely to generate a greater research focus on the health concerns of later life. In the clinical setting. an increased understanding of chronic illnesses and geriatric patients should eventually result in improved diagnoses and more holistic treatment recommendations; specially trained health care personnel should also be better equipped to assist the elderly and the lay care network to participate more effectively in the health care process.

The inadequacies of past professional training in dealing effectively with the health care needs of the elderly have been an important stimulant to the development of a geriatric focus in professional training. Similarly, the ineffectiveness of general health care policies in addressing the chronic diseases of late life has led to a more specialized emphasis on geriatric and long-term care needs. Policy experimentation with this focus has become more widespread. Several industrialized countries have begun to 
implement major changes in health care policy and reimbursement practices for long-term care. In still other countries, similar changes are either under consideration or in a demonstration phase. Such major efforts to restructure health care systems to accommodate the complexities of chronic im. pairment again reflect a recognition that traditional systems based on acute-care models do not work.

However, just as the concept of self-care has been superficially advocated at times for cost-containment rather than for health considerations. fiscal policies have been implemented which run counter to selfcare enhancing services. For example, changes in reimbursement policies, such as the ones recently enacted in the United States. focus even more on medical condition or diagnosis, rather than on level of disability or functioning. while it remains clear that functional health status and availability of family or other social supports are frequently more critical than medical diagnosis in determining formal service needs. The important research priority is, of course, to demonstrate this in a quantitative way which will be useful for policy formulation. It will also be necessary to demonstrate the necessity for changing outcome criteria from a disease (control) model to that of health maintenance improvement. This is clearly a direction which reinforces the need for enhancing self-care.

The world is obviously in a very critical transitional period in the evolution of health care policy-- a period with uncertain outcomes. It is also a time when entitlement to adequate health care and maintenance is at risk. especially for older persons. Despite serious fiscal concerns, the growing size of the world's elderly population and a prevailing humanistic attitude in many societies of the world, however, may be more influential in determining a course of action which includes a geriatric imperative.

The growth of interest in self-care during this same period suggests that the ultimate resolution of current long-term care policy dilemmas will, more likely than not, include a broader range of care options in addition to the traditional medical professional approaches. Despite this somewhat optimistic view, self-care represents a 'two-edged sword' for the elderly. For many-especially the younger, healthier, and generally better-off elderly group-enhancing self-care will be a tool of prevention, health maintenance, and consumer protection. For many others among the chronically-impaired and the very old, self-treatment may be their only, and often inadequate recourse. As noted by some observers, self-care initiatives and self-help movements may only contribute to expanding inequities in access to care [36]. An individualist attitude in many societies can work against the significant health care needs of individuals with the greatest dependencies and impairments. Those who warn against an oversimplification of self-care and its outcomes have recognized the significant negative effects which result from creating such a victim-blaming ideology $[36,37]$.

\section{CONCLLSION}

From our review and analysis of self-care among clderly populations in different countries, it seems clear that this issue will continue to receive greater attention within the context of a range of health care and social support options for the elderly [9]. It is likely that the present diversity in how self-care behavior is focused and fostered will continue to depend on cultural and economic differences within countries. It appears certain. however. that more holistic health care options for the elderly will gain greater acceptance increasing the potential for a wide range of informal care. Moreover, there is an emerging realization that the increasing demand for health care and support services by the chronically-impaired elderly may far exceed the capacity of professional care resources. Policies and services which support informal caregiving and effective self-care strategies for the elderly will become more essential everyuhere, and not just in sparsely populated regions, developing countries, and communities with fewer institutional care resources.

More holistic approaches will also require achieving a balance in fiscal allocations for the full range of health care and social services [12]. Iforeover, fiscal incentives will be required in many health care systems to further de-emphasize institutional care in favor of services which facilitate health maintenance, preventive care and positive health behavior [9].

The important role of self-care for the protection of autonomy among the elderly suggests further the need for policy initiatives which will emphasize the participatory role of older people in decisions about their own care. As Kane and Kane have suggested, it would be a contradiction to place the responsibility for self-care only with health care professionals [35]. If the reformulation of health care policies were to encourage self-treatment as the only alternative to professional services in some areas, then selttreatment would become a forced-choice for older consumers. There is obviously a balance required to assure that self-care does not become another tool in the hands of professionals only to further distance themselves from geriatric care. It is very clear, however, that inappropriate geriatric care results from both too little and too much professional intervention $[14,18]$. The objectives of policies and programs which encompass self-care should continue to emphasize the relationship between lay competence and effective decision-making in determining both health risks and care needs-regardless of its source.

Thus, the responsibility for fostering self-care efforts rests with all sides, with specific societal con. straints and situational contexts determining differential responsibility among older consumers, families, health care professionals, and policymakers. When the conservative ideologic balance is redressed, as history suggests it will be, support groups and lay activism for geriatric health care will be firmly established in the continuum of health care behavior. In fact, if anything, the prevailing conservative views in many countries have contributed to the forces which have been encouraging the self-care trend.

\section{REFERENCES}

1. Mechanic D. Medical Sociology: Free Press, New York. 1968.

2. Kasl S. V. and Cohb S. Health behavior. illness behav- 
ior, and sick-role behavior. Archs environ. Hith 12 , 246-266 and 531-541, 1966.

3. Katz A. and Bender E. The Strength in Us: Self-Help Groups In The Modern World. Franklin-Watts. New York, 1976.

4. Levin L. S., Katz A. H. and Holst E. Self-Care: Lay Initiatives in Health. Prodist, New York, 1967

5. Katz A. Self-care and seif-help programs for elders In Self-Care and Health in Old Age (Edited by Dean K et al.). Croom-Helm, London, 1986.

6. Chrisman N. and Kleinman A. Popular health care, social networks, and cultural meanings: the orientation of medical anthropology. In Handbook of Health Health Care, and the Health Professions (Edited by Mechanic D.), pp 569-590. Free Press, New York, 1983.

7. Dean K., Holst E. and Wagner M. Self-care of common illness in Denmark. Med. Care 21, 1012-1020, 1983.

8. Dean K. Self-care behavior: implications for aging In Self-Care and Health in Old Age (Edited by Dean K. et al.). Croom-Helm, London, 1986.

9. Dean K., Hickey T. and Holstein B. E. Self-Cure and Health in Old Age. Croom-Helm, London. 1986.

10. Levin L. S. and Idler E. The Hidden Health Care System. Ballinger, Cambridge, Mass., 1981

11. Levin L. S. Self-care and health planning. Soc. Policy November/December, 47-54, 1977.

12. Hickey T. Health and Aging. Brooks Cole, Monterey, Calif. 1980

13. Ford G. Old people's behavioral responses to illness. In Self-Care and Health in Old Age (Edited by Dean K. et al.). Croom-Helm. London. 1986.

14. Haug M. Elderly Patients and Their Doctors. Springer, New York. 1981.

15. Linn M. W. Linn B. S. and Stein S. R. Satisfaction with ambulatory care and compliance in older patients. Med. Care 20, 606-6l4, 1982

16. Rakowski W. and Hickey $T$. Late life health behavior integrating health beliefs and temporal perspectives. Res. Aging 2, 283-308, 1980.

17. Breslow L. A. A positive strategy for the nation's health. Proceedings of the National Health Forum. National Health Council. New York, 1979.

18. Haug M. Doctor-patient relationships and their impact on elderly self-care. In Self-Care and Health in Old Age (Edited by Dean K. et al.). Croom-Helm, London, 1986.

19. Estes C. L., Gerard L. E., Zones J. S. and Swan J. H. Political Economy, Health, and Aging. Little, Brown, Boston, Mass., 1984

20. Terris $M$. The three world systems of medical care: trends and prospects. Wld Hlth Forum 1, 78-86, 1980

21. World Health Organization. Health Policy Aspects of
Aging. Report to the World Assembly on Aging. Vienna, 1982

22. Beattie W. M. Aging: the developed and eeveloping world. Report prepared for the Lnited Nations Fund for Population Activities. United Nations, New York, 1978

23. World Health Organization. Introductory Document Demographic Considerations, Report to the World Assembly on Aging. Vienna, 1982.

24. Minkler $M$. Blaming the aged victim: the poitics of scapegoating in times of fiscal conservatism. Int. J. Hlth Serv. 13, 155-168, 1983.

25. Walker A Community care and the elderly in Great Britain: theory and practice. Int. J. Hlth Ser. 11, 547-557. 1981

26. Gough I. The crisis of the British welfare state. Int. $J$ Flth Serv. 13, 459-477, 1983.

27. Navarro $V$. Selected myths guiding the Reagan administration's health policies. Int. J. Hith Sert. 14, 321--328. 1984.

28. Estes C. L. Austerity and aging in the United States: 1980 and beyond. Int. J. Hith Serc. 12, 573-584, 1982

29. Preston S. H. Children and the elderly: divergent paths for America's dependents. Demography 21, 435-456. 1984

30. Cantor M. and Little V. Aging and social care. In Handbook of Aging and The Social Sciences (Edited by Binstock R. H. and Shanas E.), pp. 748-781, Van Nostrand Reinhold, New York, 1985

31. Abrams M. Beyond Three Score and Ten. Age Concern. London, 1978.

32. Sehnert K. W. and Eisenberg H. How to Be Your Own Doctor (Sometimes). Grosset \& Dunlap. New York. 1975 .

33. Sehnert K. W., Aukward B. and Lesage D. The Senior Citizen As An "Activated Patient". Mimcographed book prepared for the Office of Assistant Secretary for Planning and Evaluation, U.S. Public Health Service. Department of Health, Education and Welfare Washington. D.C. March, 1976.

34. Butler R. N., Gertman J. S., Oberlander D. L. and Schindler L. Self-care, self-belp, and the elderly. Int. $J$ Aging Human Devl. 10, 95-119, 1979.

35. Kane R. A. and Kane R. L. Self-care and health care: inseparable but equal for the well-being of the old. In Self-Care and Health in Old Age (Edited by Dean $\mathrm{K}$ et al.). Croom-Helm, London, 1986

36. Sidel V. W. and Sidel R. Primary health cart in relation to socio-political structure. Soc. Sci. Med. $11,415-419$ 1977

37. Crawford R. You are dangerous to your health: the ideology and politics of victim blaming. Int. J. Hith Sert. 7, 663-679, 1977. 